\title{
DOCKING OF INDOLIZINE DERIVATIVES ON CUBE RHOMBELLANE FUNCTIONALIZED HOMEOMORPHS
}

\author{
BEATA SZEFLER ${ }^{a *}$, PRZEMYSŁAW CZELEŃa \\ MIRCEA V. DIUDEA ${ }^{b}$
}

\begin{abstract}
Indolizines represent a class of heteroaromatic compounds (of pharmacological importance) containing two condensed (5- and 6-memebered) rings bridged by a nitrogen atom, showing a variety of biological activities. An attempt was made to deposit indolizines on the cube rhombellane homeomorphs surface as possible nano-drug complexes, since rhombellane homeomorphs may be bound in a protein as the active pocket and further may be used in personalized medicine. In the present study, a molecular docking analysis of two indolizine derivatives on some cube rhombellane homeomorphs was carried out for the first time.
\end{abstract}

Keywords: binding energy, indolizine, molecular docking, nanostructure, cube rhombellane homeomorph.

\section{INTRODUCTION}

In recent years, interest in modern methods of drug delivery using nanostructures has increased; drug delivery is becoming an important aspect of medicine, as more potent and specific drugs are being developed particularly with the increased understanding of disease pathways generated by the Human Genome Project. Novel materials and formulations are enabling the site-specific targeting and controlled release of traditional pharmaceuticals, recombinant proteins, vaccines and nucleic acids. Nanoscale drug-delivery systems can be devised to tune release kinetics, to regulate biodistribution and bioavailability, to minimize toxic side effects, thus enhancing the therapeutic efficiency of a given drug [1-5].

a Department of Physical Chemistry, Faculty of Pharmacy, Collegium Medicum, Nicolaus Copernicus University, Kurpińskiego 5, 85-096, Bydgoszcz, Poland.

${ }^{\mathrm{b}}$ Department of Chemistry, Faculty of Chemistry and Chemical Engineering, Babes-Bolyai University, 400028 Cluj-Napoca, Romania. 
Indolizine derivatives are heteroaromatic compounds of pharmacological importance with two condensed (5- and 6-memebered) rings bridged by a nitrogen atom (Figure 1). They can inhibit enzyme activity and act as calcium entry blockers in cardiovascular activity, also they show antimicrobial, antioxidant, anti-inflammatory, tuberculostatic, antihistaminic or antitumoral properties $[6,7]$. In nature they have been isolated from animals, insects, plants, marine organisms, and microbes [8]. Synthesis of indolizines involve 1,3-dipolar cycloadditions, cyclization reactions, etc. [9].

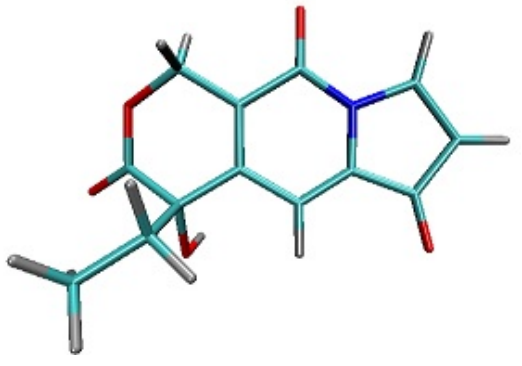

Ligand 1 (CID=359849)

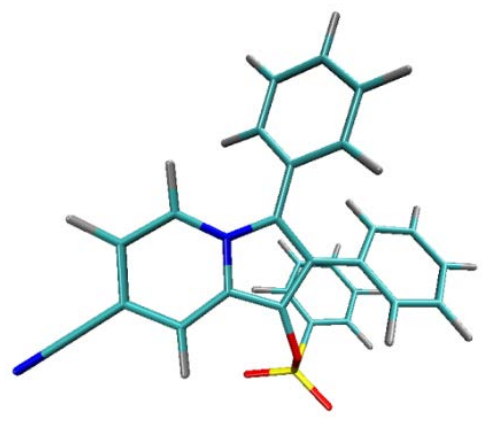

Ligand $2(\mathrm{CID}=491916)$

Figure 1. Structure of studied ligands: Ligand 1 (Lig1) with PDB Code 359849 (left) and Ligand 2 (Lig2) with PDB Code 491916 (right).

The choice of indolizine ligands was guided by our earlier studies [1012] and the use of these Indolizine derivatives as inhibitors for enzymes Beta lactamase and Nicotinamide phosphoribosyltransferase; the two ligands are: Lig1, CID=359849 and Lig2, CID=491916 (PubChem, [13]).

\section{CUBE RHOMBELLANE HOMEOMORPHS}

Rhombellanes are structures with all strong rings being rhombs/squares; they have been proposed by Diudea in 2017 [14]. [1,1,1]Propellane is an organic molecule, first synthesized in 1982 [15]; by IUPAC rules, it is named tricyclo[1.1.1.0 $0^{1,3}$ pentane, a hydrocarbon with formula $\mathrm{C}_{5} \mathrm{H}_{6}$, containing only triangles; its reduced form, $\mathrm{C}_{5} \mathrm{H}_{8}$, eventually named bicyclo[1.1.1]pentane, has only quadrilateral rings; it can be represented as $\mathrm{K}_{2,3}$ - the complete bipartite graph. The two bridge carbon atoms can be functionalized, e.g., by bromine or $\mathrm{COOH}$, or even by repeating the $\mathrm{K}_{2,3}$ motif, as in the polymer called staffane [16]. A rhombellane was defined by Diudea [17] as a structure having: 
a) All strong rings are squares/rhombs;

b) Vertex classes consist of all non-connected vertices;

c) Omega polynomial has a single term: $1 X^{\wedge}|E|$;

d) Line graph of the parent graph has a Hamiltonian circuit;

e) It contains at least one $K_{2.3}$ subgraph.

Rhombellanes are designed by the "rhombellation" procedure; it starts with diagonalizing each face of an all-rhomb map $\mathrm{Rh}_{0}$ by a joint point (called "rbl-point"); then, add new vertices opposite to the parent vertices and join each of them with the rbl-vertices lying in the proximity of each parent vertex, thus local Rh-cells being formed. The process can continue, considering the envelope $R h_{n}$ as " $R h_{0}$ " for $R h_{n+1}$, in this way shell by shell being added to the precedent structure. Since the two diagonals of a rhomb may be topologically different, each generation may consist of two isomers. Construction of the cube-rhombellane (1) is illustrated in Figure 2, left. Each square face forms a $\mathrm{K}_{2.3}$ rhombellane by joining the opposite corners with homeomorphic diagonals; these diagonals are joint together in an adamantane motif (in red); $\mathrm{K}_{2.3}$ and adamantane are both "tiles", not polyhedra.

A homeomorph of a graph contains on each parent edge one (or more) point(s) of degree two, see for example, the cube homeomorph (2) in Figure 2 (middle). The structure (3), which is the homeomorph of (1) has seventy points/atoms, as illustrated in Figure 1 (right); the vertex connectivity in (3) is $6 ; 3$ and 2 , respectively.

To synthesize (3) as a molecule, one may start from 1,2,3,4,5,6Hexahydroxy-cyclohexane, that may form an ether (4) (Figure 3), which is a (hyper) homeomorph of the cube (2) and the "core" of $r b /(\mathrm{C})$-homeomorph (3); the vertices of connectivity 6 will be just the hexahydroxy-cyclohexane while the three-connected points may be 1,3,5-trihydroxy-cyclohexane or its derivatives (e.g., hexahydroxy- cyclohexane, 1,3,5-trihydroxy-benzene, etc.).

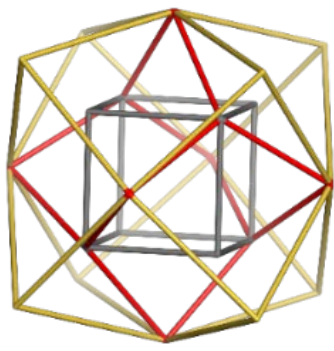

$r b /(C) ; v=22$

(1)

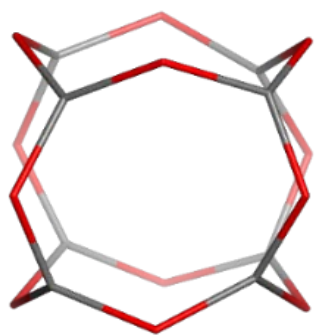

Cube homeomorph; $v=20$

(2)

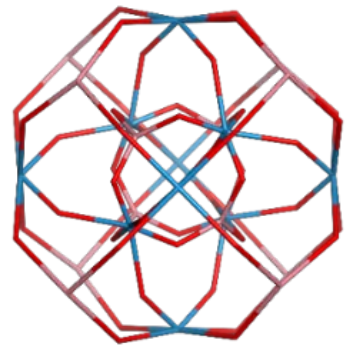

rbl(C)-homeomorph; $\mathrm{v}=70(3)$

Figure 2. Cube-rhombellane and related structures ( $v=$ no. vertices/atoms). 
Note that silsesquioxanes are synthesized molecules having a core homeomorph of the cube (2) $[18,19]$.

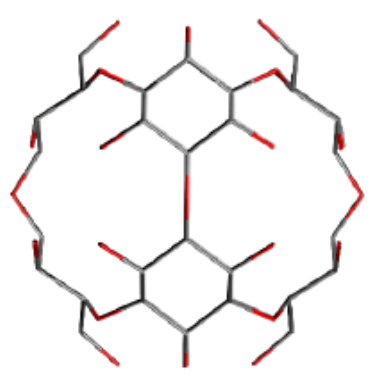

2

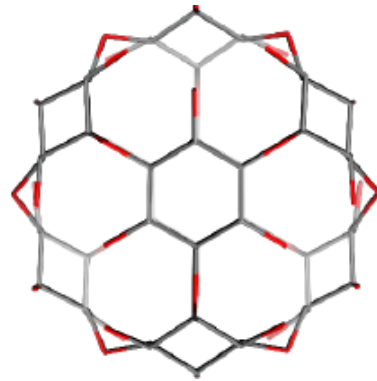

3

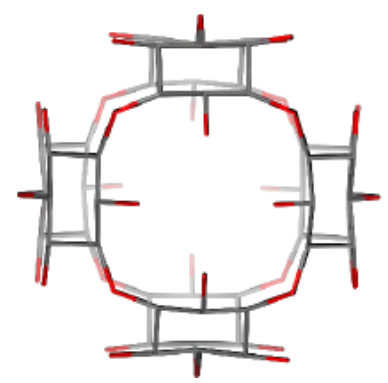

4

Figure 3. Cube-rbl (ether) core (4), v=156; in 2-, 3- and 4-fold symmetry, respectively.

\section{ADA-MOTIF AND FUNCTIONALIZED RHOMBELLANES.}

Cube-rbl homeomorphs comprise a hyper-adamantane motif, ADArbl (5) (Figure 4, left); including a Cube-rbl-core and completing the external shell (by adding 8 tri-connected units), one obtains complete the Cube-rblamide (6)/ester(7) structures (Figure 4, middle and right). Specification of the herein discussed Diudea's structures [20] is given in Table 1.

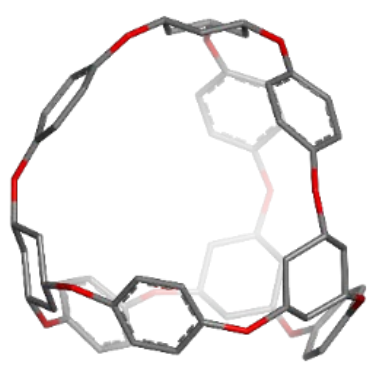

ADA-132 (5)

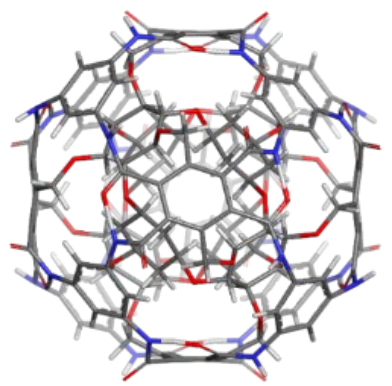

372 (6)

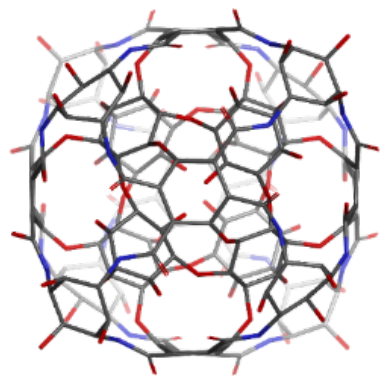

456 (7)

Figure 4. ADA-rbl intermediate and Cube rhombellane homeomorphs (functionalized). 
Table 1. Cube rhombellane homeomorph derivatives: $v=$ no. vertices/atoms; elemental composition, structure and type.

\begin{tabular}{ccccccccc}
\hline $\mathbf{v}$ & $\mathbf{C}$ & $\mathbf{N}$ & $\mathbf{O}$ & $\mathbf{H}$ & Structure & Type I & Type II & Type III \\
\hline 144 & 48 & 12 & 0 & 84 & Core & Ether & $6(6) 6(3)$ & in-in; in-ex; ex-ex \\
156 & 48 & 12 & 12 & 84 & Core & Ether & $6(6) 6(6)$ & in-in; in-ex; ex-ex \\
\hline 132 & 60 & 0 & 12 & 60 & ADA-rbl & Ether & $6(3) ; \mathrm{B}(2)$ & - \\
\hline 360 & 168 & 0 & 84 & 108 & C-rbl & Ester & $6(6) ; 6(6)$ & B(3) \\
372 & 168 & 24 & 48 & 132 & C-rbl & Amide & $6(6) ; 6(3)$ & B(3) \\
396 & 192 & 0 & 72 & 132 & C-rbl & Ester & $6(6) ; \mathrm{B}(3)$ & $\mathrm{B}(3) \mathrm{M}$ \\
420 & 192 & 24 & 48 & 156 & C-rbl & Amide & $6(6) ; \mathrm{B}(3)$ & $\mathrm{B}(3) \mathrm{M}$ \\
444 & 192 & 24 & 48 & 180 & C-rbl & Amide & $6(6) ; 6(3)$ & $\mathrm{B}(3) \mathrm{M}$ \\
456 & 156 & 24 & 84 & 192 & C-rbl & Amide & $6(6) ; 6(6)$ & $\mathrm{B}(3) \mathrm{M}$ \\
\hline
\end{tabular}

Name of Cube rhombellane homeomorphs: $\mathrm{Rbl}(\mathrm{C})-(6(6), \mathrm{x}(\mathrm{y}))-\mathrm{B}(3) \mathrm{z}-\mathrm{ester} / \mathrm{amide}$

\section{METHOD}

In the docking procedure, the molecules were loaded and stored as pdb-files, after assigning hydrogen bonds [21], using the AutoDockVina software [22]. The investigated ligands were loaded and their torsions along the rotatable bonds were assigned, then the files were saved as "ligand.pdbqt". The grid menu was next toggled [23]; after loading "pdbqt", the map files were selected directly with setting up the grid points, for the search of ligand-rbl interactions, separately for each structure. The docking parameter files were completed by using the Lamarckian genetic algorithm [24]. As a reference structure the fullerene $\mathrm{C}_{60}$, the most referred structure in Nanoscience was considered.

\section{RESULTS AND DISCUSSION}

The results are presented in the following tables and figures. Rhombellane structures are given by their atom number. 
Table 2. Binding affinity of ligand Lig1, CID $=359849$, with the active site of Rbl-nano-structures (first column) during nine conformations.

\begin{tabular}{ccccccccccc}
\hline Cube Rbl & $\mathbf{1}$ & $\mathbf{2}$ & $\mathbf{3}$ & $\mathbf{4}$ & $\mathbf{5}$ & $\mathbf{6}$ & $\mathbf{7}$ & $\mathbf{8}$ & $\mathbf{9}$ & $\begin{array}{c}\text { Docked } \\
\text { energy } \\
\text { (kcal/mol) }\end{array}$ \\
\hline 144_ex_ex & -2.8 & -2.8 & -2.8 & -2.8 & -2.8 & -2.8 & -2.8 & -2.8 & -2.8 & -2.8 \\
144_in_ex & -3 & -3 & -3 & -3 & -3 & -3 & -3 & -3 & -3 & -3 \\
156_ex_ex & -3.1 & -3.1 & -3.1 & -3.1 & -3.1 & -3.1 & -3.1 & -3.1 & -3.1 & -3.1 \\
156_in_ex & -3.3 & -3.3 & -3.3 & -3.3 & -3.3 & -3.3 & -3.2 & -3.2 & -3.2 & -3.3 \\
360 & -4.7 & -4.7 & -4.7 & -4.7 & -4.7 & -4.7 & -4.7 & -4.6 & -4.6 & -4.7 \\
372 & -4.6 & -4.6 & -4.6 & -4.6 & -4.6 & -4.6 & -4.6 & -4.5 & -4.5 & -4.6 \\
396 & -4.1 & -4.1 & -4.1 & -4.1 & -4.1 & -4.1 & -4.1 & -4.1 & -4.1 & -4.1 \\
420 & -3.9 & -3.9 & -3.9 & -3.9 & -3.9 & -3.9 & -3.9 & -3.9 & -3.9 & -3.9 \\
444 & -4 & -4 & -3.9 & -3.9 & -3.9 & -3.9 & -3.9 & -3.9 & -3.9 & -4 \\
456 & -4.1 & -4 & -4 & -4 & -4 & -4 & -4 & -4 & -4 & -4.1 \\
ADA_132 & -3.2 & -3.2 & -3.2 & -3.2 & -3.2 & -3.2 & -3.2 & -3.2 & -3.2 & -3.2 \\
C60 & -4.3 & -4.3 & -4.3 & -4.3 & -4.3 & -4.3 & -4.3 & -4.3 & -4.3 & -4.3 \\
\hline
\end{tabular}

The most of binding affinity values for all complexes Ligand 1 $(C I D=359849)-$ Rhombellane are lower compared with the value exhibited by the complex Ligand $1-\mathrm{C}_{60}(-4.3 \mathrm{kcal} / \mathrm{mol}-$ Table 2$)$ and lower compared with complexes Ligand 2 - Rhombellane (Table 3).

Only 360 and 372 structures form stronger complexes with Ligand 1 compared to $\mathrm{C}_{60}(-4.7$ and $-4.6 \mathrm{Kcal} / \mathrm{mol}$, respectively).

The best affinity Ligand $2(\mathrm{CID}=491916)$ to Cube-rhombellanes is showed in case of 396 affinity value $-5.4 \mathrm{kcal} / \mathrm{mol}$ - Table 3). A little lower value was recorded for 372 and 360 structures ( -5 and $-4.9 \mathrm{kcal} / \mathrm{mol}$, respectively). The energy of interaction between Lig 2 and $\mathrm{C}_{60}$ is $-4.9 \mathrm{kcal} / \mathrm{mol}$. In general, the values of binding affinity are higher for the Lig2 than Lig1. (compare Table 2 with Table 3). 
Table 3. Binding affinity of ligand Lig2, CID=491916, with the active site of Rbl-nano-structures (first column) during nine conformations.

\begin{tabular}{ccccccccccc}
\hline Cube Rbl & $\mathbf{1}$ & $\mathbf{2}$ & $\mathbf{3}$ & $\mathbf{4}$ & $\mathbf{5}$ & $\mathbf{6}$ & $\mathbf{7}$ & $\mathbf{8}$ & $\mathbf{9}$ & $\begin{array}{c}\text { Docked } \\
\text { energy } \\
\text { (kcal/mol) }\end{array}$ \\
\hline 144_ex_ex & -2.9 & -2.9 & -2.9 & -2.9 & -2.9 & -2.9 & -2.9 & -2.9 & -2.9 & -2.9 \\
144_in_ex & -3.5 & -3.5 & -3.5 & -3.5 & -3.5 & -3.5 & -3.5 & -3.5 & -3.4 & -3.5 \\
156_ex_ex & -3.5 & -3.5 & -3.5 & -3.5 & -3.5 & -3.5 & -3.5 & -3.5 & -3.5 & -3.5 \\
156_in_ex & -3.8 & -3.8 & -3.8 & -3.8 & -3.8 & -3.8 & -3.8 & -3.8 & -3.8 & -3.8 \\
360 & -4.9 & -4.8 & -4.8 & -4.8 & -4.8 & -4.8 & -4.8 & -4.7 & -4.7 & -4.9 \\
372 & -5 & -4.9 & -4.9 & -4.9 & -4.9 & -4.9 & -4.9 & -4.9 & -4.8 & -5 \\
396 & -5.4 & -5.4 & -5.4 & -5.4 & -5.4 & -5.4 & -5.4 & -5.3 & -5.3 & -5.4 \\
420 & -4.6 & -4.6 & -4.6 & -4.6 & -4.6 & -4.5 & -4.5 & -4.5 & -4.5 & -4.6 \\
444 & -4.8 & -4.8 & -4.8 & -4.7 & -4.6 & -4.6 & -4.6 & -4.6 & -4.6 & -4.8 \\
456 & -4.8 & -4.8 & -4.8 & -4.8 & -4.7 & -4.7 & -4.6 & -4.6 & -4.6 & -4.8 \\
ADA_132 & -4 & -4 & -4 & -4 & -3.9 & -3.9 & -3.9 & -3.9 & -3.9 & -4 \\
C60 & -4.9 & -4.9 & -4.9 & -4.9 & -4.9 & -4.9 & -4.9 & -4.9 & -4.9 & -4.9 \\
\hline
\end{tabular}

Percentage deviations of the affinity values of the ligands Lig1 and Lig2 were estimated for the tested Rbl-structures in relation to the affinity value obtained for the fullerene $\mathrm{C}_{60}$. The highest positive percentage deviations from the affinity of Lig1 and Lig2 to fullerene $\mathrm{C}_{60}$ were obtained for those Rblstructures showing the highest binding values (Table 4, column 4 and 5 - in boldface).

Two last columns show the equilibrium $\mathrm{K}$ value of the bonds, calculated by:

$$
K_{B}=\exp \left(\frac{-\Delta G_{B}}{\mathrm{RT}}\right),
$$

where: $\mathrm{Kb}$ is binding constant, $\mathrm{R}$ - gas constant $\left(\mathrm{J} / \mathrm{mol}^{*} \mathrm{~K}\right), \mathrm{T}$ - temperature $298 \mathrm{~K}$, - $\Delta \mathrm{Gb}$ binding affinity $(\mathrm{J} / \mathrm{mol})$. The higher the $\mathrm{K}$ value the more the reaction proceeds towards the formation of the complex.

Detailed analysis of structural properties after docking showed that the affinity of the ligands to the Rhombellanes surface are correlated with the quality of hydrogen bonds formed between them and stacking interactions between aromatic rings of ligands and aromatic rings of Rhombellanes. 
Table 4. The best binding affinity of ligands: Lig1 and Lig2, the percentage difference in binding affinity relative to ligand-fullerene $\mathrm{C}_{60}$ (namely affinity), $\mathrm{K}$ - constant binding balance.

\begin{tabular}{ccccccc}
\hline Cube Rbl & $\begin{array}{c}\text { The best } \\
\text { binding affinity } \\
\text { (kcal/mol) }\end{array}$ & $\begin{array}{c}\text { \% difference in binding } \\
\text { affinity relative to } \\
\text { ligand-fullerene C60 }\end{array}$ & \multicolumn{2}{c}{$\begin{array}{c}\text { K - constant } \\
\text { binding } \\
\text { balance }\end{array}$} \\
\hline Lig1 & Lig2 & Lig1 & Lig2 & Lig1 & Lig2 \\
\hline 144_ex_ex & -2.8 & -2.9 & -34.9 & -40.8 & 111.4 & 131.8 \\
144_in_ex & -3 & -3.5 & 69.8 & 71.4 & 156.0 & 361.9 \\
156_ex_ex & -3.1 & -3.5 & -27.9 & -28.6 & 184.6 & 361.9 \\
156_in_ex & -3.3 & -3.8 & -23.3 & -22.4 & 258.5 & 599.7 \\
360 & -4.7 & -4.9 & 9.3 & 0.0 & $\mathbf{2 7 2 8 . 3}$ & 3820.3 \\
372 & -4.6 & -5.0 & 7.0 & 2.0 & 2305.6 & 4520.7 \\
396 & -4.1 & -5.4 & -4.7 & 10.2 & 993.7 & $\mathbf{8 8 6 3 . 8}$ \\
420 & -3.9 & -4.6 & -9.3 & -6.1 & 709.7 & 2305.6 \\
444 & -4.0 & -4.8 & -7.0 & -2.0 & 839.8 & 3228.5 \\
456 & -4.1 & -4.8 & -4.7 & -2.0 & 993.7 & 3228.5 \\
ADA_132 & -3.2 & -4.0 & -25.6 & -18.4 & 218.4 & 839.8 \\
C60 & -4.3 & -4.9 & 0.0 & 0.0 & 1391.5 & 3820.3 \\
\hline
\end{tabular}

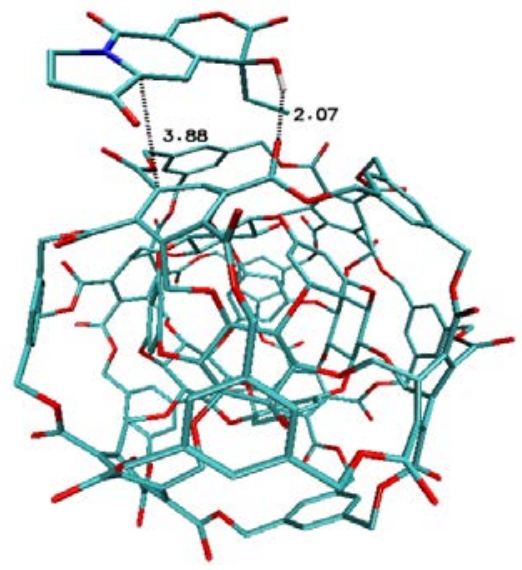

396-Lig1

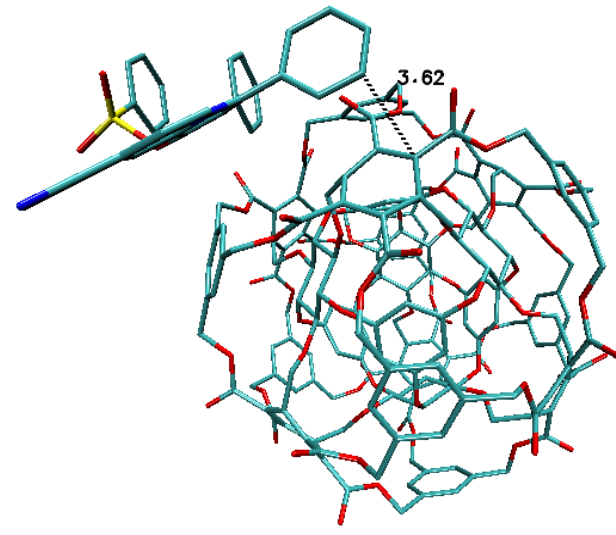

396-Lig2

Figure 5. Interactions found in the complexes of Rhl-396 and ligands Lig1 (left) and Lig2 (right) after the docking procedure. 
In case of ligand Lig1 and the Rbl-396, the distance between the aromatic system of the ligand and the aromatic system of $R b l$ is $3.88 \AA$, what allows to form a hydrogen bond with the carbonyl oxygen atom, with a bond distance of $2.07 \AA$. In case of ligand Lig2 the distance between the aromatic system of ligand and that of $\mathrm{Rbl}$ is $3.62 \AA$ (Figure 5 ).

After the docking of Rbl-372 with Lig1, the distance between the aromatic system of ligand and $\mathrm{Rbl}$ is $3.40 \AA$, what favorizes the creation of a strong hydrogen bond with the carbonyl oxygen atom, with the length of 2.23 $\AA$; the distances between the aromatic systems of Lig2 and Rbl is greater $(4.14 \AA)$, that's why two weaker interactions Lig2 - Rbl-372 appeared (with the length $4.20 \AA$ and $3.59 \AA$, respectively - Figure 6).

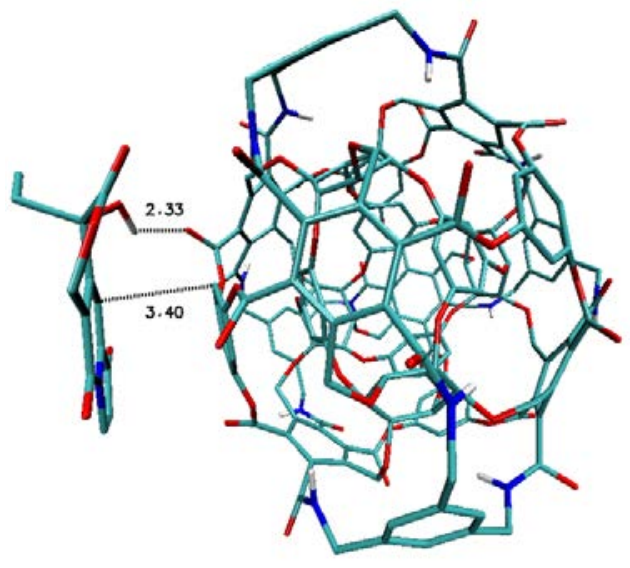

372- Lig1

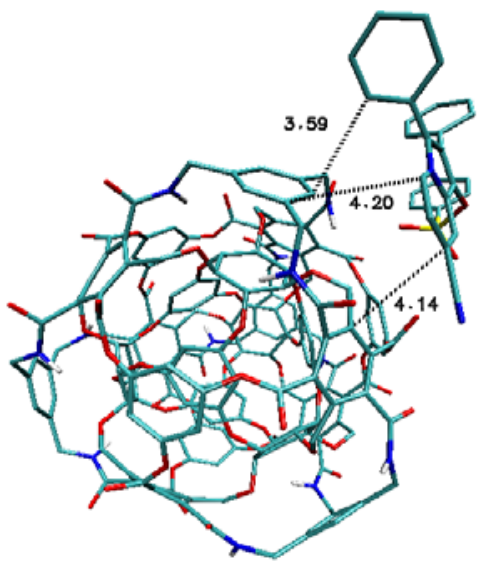

372- Lig2

Figure 6. Interactions found in the complexes of Rhl-372 and ligands Lig1 (left) and Lig2 (right) after the docking procedure.

The distance between the aromatic rings of Lig1 and Rbl-360 is 3.59 $\AA$, what gives the opportunity to create two kinds of hydrogen bonds with carbonyl oxygen atoms, with the length 2.43 and $2.92 \AA$, respectively. In case of Lig2, the distance between the two aromatic systems is $3.67 \AA$ (Figure 7).

After docking, the interactions of Lig1 and Lig2 with the fullerene $C_{60}$ were tested, as a reference structure; the manifested stacking interactions resulted in distance 3.60 and $3.75 \AA$, respectively (Figure 8). 


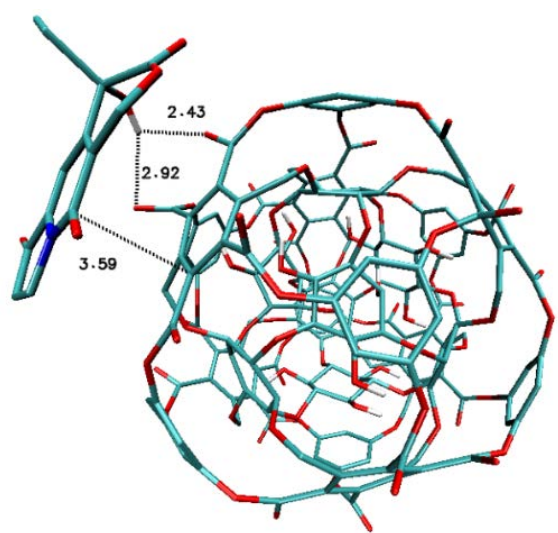

360- Lig1

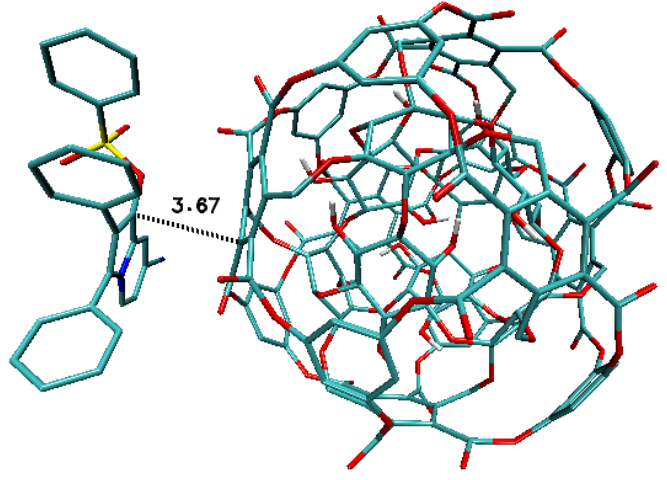

360- Lig2

Figure 7. Interactions found in the complexes of Rhl-360 and ligands Lig1 (left) and Lig2 (right) after the docking procedure.

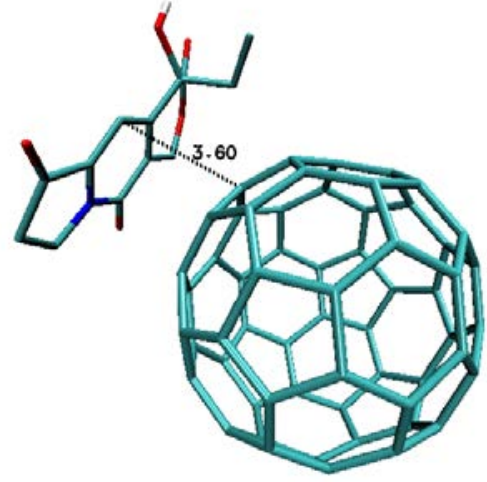

$\mathrm{C}_{60}$ - Lig1

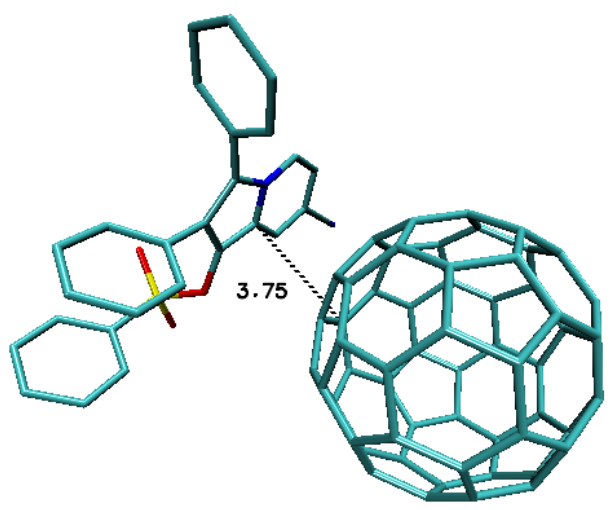

$\mathrm{C}_{60}-\mathrm{Lig} 2$

Figure 8. Interactions found in the complexes of fullerene $\mathrm{C}_{60}$ and ligands Lig1 (left) and Lig2 (right) after the docking procedure.

\section{CONCLUSIONS}

An attempt was made to deposit the indolizine ligands on the Cube Rhombellane homeomorphs surface as a proposal of a new nano-drug. 
The most of binding affinity values for all complexes Ligand 1 $(C I D=359849)$ - Rhombellane are lower compared with the corresponding values for the complex Ligand $1-\mathrm{C}_{60}(-4.3 \mathrm{kcal} / \mathrm{mol}$, Table 2$)$ and lower compared with those for the complexes Ligand 2 - Rhombellane (Table 3). Only Rbl-360 and Rbl-372 structures form stronger complexes with Lig1 compared to $\mathrm{C}_{60}$. The best affinity was shown in case of Rbl-360 $(-4.7 \mathrm{kcal} / \mathrm{mol})$. Only a little low value was shown by the complex Lig2 - Rbl-372(-4.6 kcal $/ \mathrm{mol})$; the reference complex Lig1- $\mathrm{C}_{60}$ energy has $-4.3 \mathrm{kcal} / \mathrm{mol}$. The best affinity was recorded for the complex Lig2 - Rbl-396 $(-5.4 \mathrm{kcal} / \mathrm{mol})$, followed by the complexes Lig2-Rbl-372 and Lig2-Rbl-360 ( -5 and $-4.9 \mathrm{kcal} / \mathrm{mol}$, respectively). The energy of interaction between Lig 2 and $\mathrm{C}_{60}$ is $-4.9 \mathrm{kcal} / \mathrm{mol}$. Different order of affinity values can be observed among the complexed made by the two ligands with the Rhombellanes.

Percentage deviations of the affinity value of the ligands Lig1 and Lig2 were estimated for the data obtained on the tested Rhombellanes, in relation with the affinity value obtained for the fullerene $C_{60}$. The highest positive percentage deviations were obtained for Lig-Rbl complexes showing the highest binding energy values.

Detailed analysis of structural properties after docking showed that the values of affinity of the studied indolizine ligands to the Rhombellanes surface are correlated with the strength/length of hydrogen bonds formed between them, first of all caused by the stacking interactions between aromatic rings of ligands and aromatic rings of Rhombellanes.

\section{ACKNOWLEDGEMENTS}

This research was supported by PL-Grid Infrastructure (http://www.plgrid.pl/en)

\section{REFERENCES}

1. Q. Long, Y. Xiel, Y. Huang et al., Journal Biomedical Nanotechnology, 2013, 9, 965.

2. M. Benezra, O. Penate-Medina, P.B. Zanzonico, et al. Journal of Clinical Investigation, 2011, 121, 2768.

3. H. Ali-Boucetta, K. T. Al-Jamal, D. McCarthy et al,. Chemical Communications, 2008, $28,459$.

4. S. Sánchez-Paradinas, M. Pérez-Andrés, M.J. Almendral-Parra, et al., Journal of Inorganic Biochemistry, 2014, 131, 8. 
5. M. P. Evstigneev, A. S. Buchelnikov, D. P. Voronin, Y. V. Rubin, L. F. Belous, Y. I. Prylutskyy, U. Ritter, Chem. Phys. Chem., 2013, 14, 568.

6. G. S. Singh, E. E. Mmatli, European Journal of Medicinal Chemistry, 2011, 46, 5237.

7. S. S. Juang, M. Chang, L. F. Wang, J. L. Han, C. H. Ong, Tetrahedron, 2005, 61, 1693.

8. T. Przewloka, S. Chen, Z. Xia, H. Li, S. Zhang, D. Chimmanamada, E. Kostik, D. James, K. Koya, L. Sun, Tetrahedron Lett., 2007, 48, 5739.

9. I. V. Seregin, A. W. Schammel, V. Gevorgyan, Tetrahedron, 2008, 64, 6876.

10. B. Szefler, T. E. Harsa, A. M. Harsa, Studia UBB Chemia, 2015, 60, 201.

11. B. Szefler, P. Czeleń, M. V. Diudea, Current Computer-Aided Drug Design, 2017, 13, 22.

12. B. Szefler, P. Czeleń, Journal. Molecular Modeling, 2017, 23, 208.

13. PubChem database, accessed 10. 10. 2014.

14. M. V. Diudea, Intl. Conf. "Bio-Nano-Math-Chem", 2017, Cluj, Romania.

15. K. B. Wiberg, F. H. Walker, [1.1.1]Propellane, Journal of American Chemical Society, 1982, 104, 5239.

16. P. Kazynsky, J. Michl, Journal of American Chemical Society, 1988, 110, 5225.

17. M. V. Diudea, Iranian Journal of Mathematical Chemistry, 2018, 9, 1.

18. D. R. Do Carmo, L. L. Paim, N. L. Dias Filho, N. R. Stradiotto, Applied Surface Science, 2007, 253, 3683.

19. D. R. Do Carmo, U. O. Bicalho, T. F. Silveira, N. L. Dias Filho, L. L. Paim, Journal of Chemistry, 2013, 2, 1.

20. M. V. Diudea, International Journal of Chemical Modeling, 2018, 9, 2, 000.

21. O. Trott, A. J. Olson, Journal Computer Chemistry, 2010, 31, 455.

22. B. K Shoichet, I. D. Kuntz, D. L. Bodian, Journal Computer Chemistry, 2004, 13, 380.

23. K. Dhananjayan, K. Kalathil, A. Sumathy, P. Sivanandy, Der Pharma Chemica, 2014, 6, 378.

24. R. Abagyan, M. Totrov, Current Opinion in Chemical Biology, 2001, 5, 375. 